NISTIR 8162

\title{
Automation of Piston Gauge Calibration Services Phase I Results
}

\author{
Katie Schlatter \\ John Quintavalle \\ C. Dawn Cross \\ R. Gregory Driver \\ Julia Scherschligt
}

This publication is available free of charge from: https://doi.org/10.6028/NIST.IR.8162 


\title{
Automation of Piston Gauge Calibration Services Phase I Results
}

\author{
Katie Schlatter \\ John Quintavalle \\ Office of Information Systems Management \\ Julia Scherschligt \\ R. Gregory Driver \\ C. Dawn Cross \\ Sensor Science Division \\ Physical Measurement Laboratory
}

This publication is available free of charge from: https://doi.org/10.6028/NIST.IR.8162

December 2016

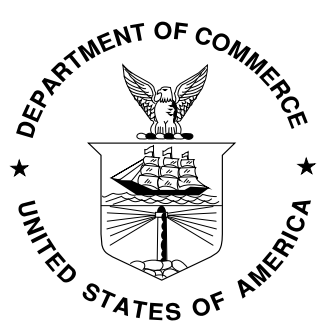

U.S. Department of Commerce Penny Pritzker, Secretary

National Institute of Standards and Technology Willie May, Under Secretary of Commerce for Standards and Technology and Director 


\section{Automation of Piston Gage CaLiBration SERVices PHASE I RESULTS}

This report documents efforts to date to automate Piston Gauge Calibration Services. This report includes an overview of the project, results for Phase I Implementation efforts, and a look ahead to Phase II. Phase I Measures and Deliverables are based on the Piston Gauge Calibration Phase I Implementation Project Charter dated 11-21-2014. All results were based on average inputs required to complete the calibration of a single 29010C Deadweight Piston Gauge.

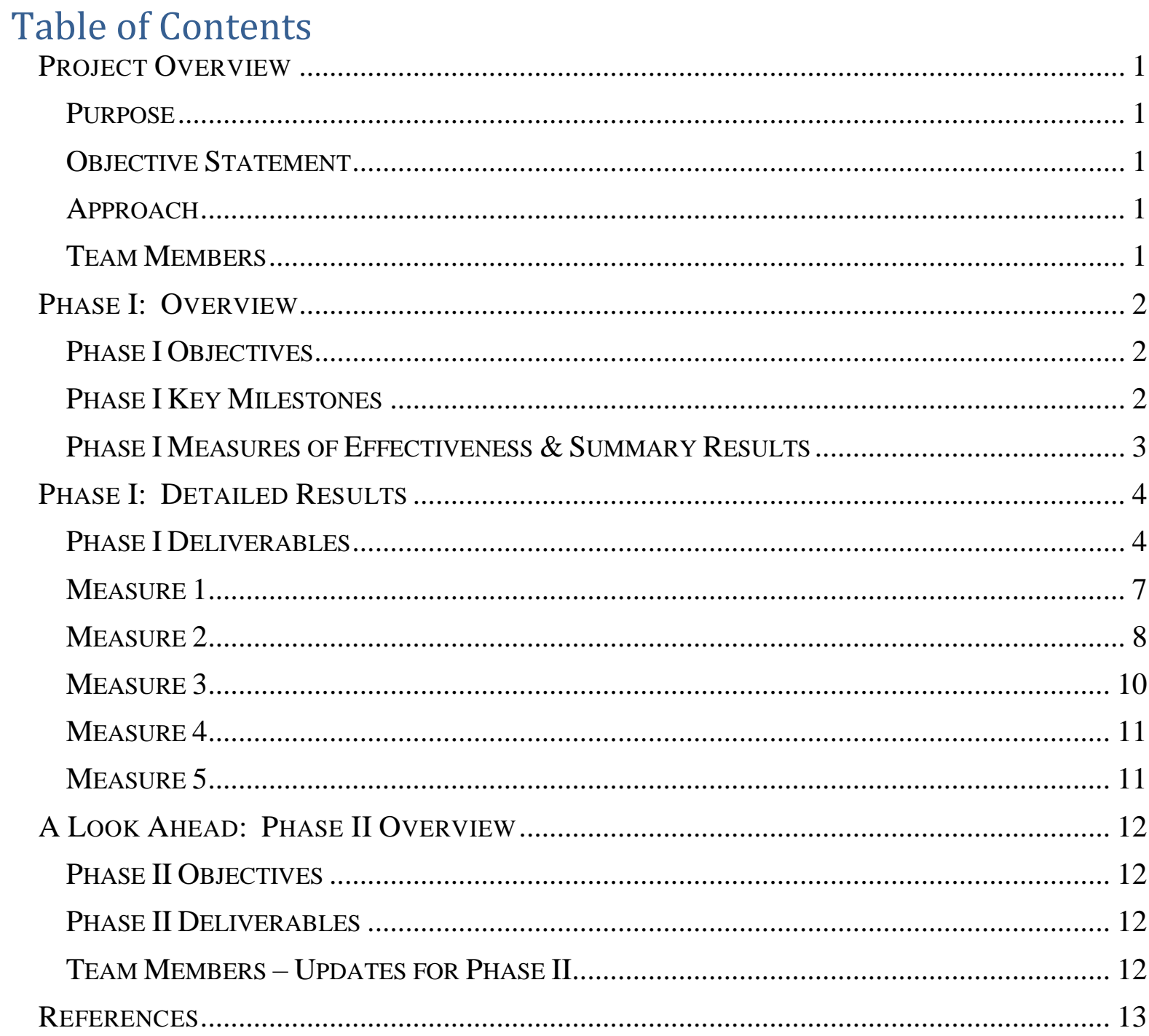




\section{PROJECT OVERVIEW}

\section{PURPOSE}

The National Institute of Standards and Technology (NIST) offers pressure calibrations for stakeholders in industry and defense that have been executed at a world-class quality level by using a labor-intensive process requiring years of experience since calibration services utilizing piston gauge pressure standards began at NIST in the 1930s. The cost of pressure calibrations has increased over time due to the requirement for highly trained labor and resulted in a reduction of available staff time for research.

\section{OBJECTIVE STATEMENT}

Improve the process for Pneumatic Deadweight Piston Gauge Calibrations (NIST service ID 29010C [1]) by minimizing manual time required by staff to execute the process, reducing the level of experience required for staff involved while maintaining (or improving) process quality, reducing the average turn-around time and reducing the total cost of pressure calibrations per Pressure ID.

\section{APPROACH}

Between April and November of 2014, the team developed process maps for both the current state and an ideal future state for the piston gauge calibration process. A gap analysis identified improvement opportunities that were prioritized and broken down into a 3-phase approach for implementation.

> Phase I - focus on replacing legacy software and manual calculations with a LabVIEW* program capable of capturing all required inputs during equipment receipt, setup and measurement, then automating data analysis and report generation. In addition, the team will develop a system to introduce a new transducer measurement method and then verify it is capable of replacing the existing trim mass measurement method.

$>$ Phase II - focus on introducing automated capture of measurement values and automated process control of the measurement process with the exception of loading and unloading masses (this will be addressed in Phase III).

$>$ Phase III - focus on implementation of an automated mass handling device which would create full automation of the measurement process once setup activities are complete.

\section{TEAM MEMBERS}

Greg Strouse $\rightarrow$ Jay Hendricks, Project Sponsor:

- Responsible for funding, physical space, sign off

Doug Olson $\rightarrow$ Julia Scherschligt, Technical Project Lead:

- Responsible for acceptance criteria, validation of product

Greg Driver, Julia Scherschligt, Process Owner / NIST Technical Contact:

- Responsible for defining requirements, facilitating knowledge transfer, defining acceptance criteria

Dawn Cross, NIST Technical Contact:

- Responsible for user acceptance testing, validation of user documentation, calibration service support upon implementation of Phase I changes

John Quintavalle, LabVIEW Developer:

- Responsible for development, system testing and implementation support

Katie Schlatter, Project Manager / Process Engineer:

- Responsible for scheduling, project management, process improvement assessment and design 
Additional Support:

Yuanchao Yang: Guest Researcher responsible for development and assembly of manifold to support new transducer method (replacing use of trim masses) ${ }^{1}$

Jacob Ricker: Subject Matter Expert for replacement of trim masses

\section{PHASE I: OVERVIEW}

Phase I focused on replacing legacy software and manual calculations with a LabVIEW program capable of capturing all required inputs during equipment receipt, setup and measurement, then automating data analysis and report generation. In parallel, the team worked to develop a new transducer measurement method capable of replacing the existing trim mass measurement method.

\section{PhASE I OBJECTIVES}

Reduce opportunities for error, time required and level of experience required in the piston gauge calibration service by:

- Combining capture of equipment receipt, measurement point calculations, setup, recording of observations, data analysis and report generation activities into one program (LabVIEW),

- Eliminating duplicate data entry points,

- Creating an electronically accessible version of Working Standard information to further reduce data entry requirements,

- Improving quality through reduction of manual input and introduction of electronic historical records,

- Improving data analysis automation to complete in one step, and

- Automating report generation.

Identify and make go/no-go decisions for solutions required for implementing:

- $100 \%$ electronic test folders, and

- Fully automated calibration process.

\section{PhaSe I Key Milestones}

\begin{tabular}{|l|c|}
\hline \multicolumn{1}{|c|}{ Milestone } & Date Completed \\
\hline Phase I Start & $12 / 1 / 2014$ \\
\hline Approval for Review \& Approval application & $9 / 18 / 2015$ \\
\hline $\begin{array}{l}\text { Confirmation trim masses can be replaced with pressure } \\
\text { transducers / absolute gauges }\end{array}$ & $10 / 12 / 2015$ \\
\hline $\begin{array}{l}\text { Go/No-go decision for development / implementation of } \\
\text { a mass handling device }\end{array}$ & $2 / 8 / 2016$ \\
\hline Phase I LabVIEW development complete & $3 / 22 / 2016$ \\
\hline Phase I LabVIEW testing complete & $7 / 26 / 2016$ \\
\hline Complete Validation Testing & $11 / 3 / 2016$ \\
\hline Implementation of Phase I LabVIEW Program & $11 / 4 / 2016$ \\
\hline
\end{tabular}

* Disclaimer: Certain equipment or materials are identified in this paper in order to specify the experimental procedure adequately. Such identification is not intended to imply endorsement by the National Institute of Standards and Technology, nor is it intended to imply that the materials or equipment identified are necessarily the best available. 


\section{Phase I Measures of EfFectiveness \& Summary ReSultS}

The team identified five measures for effectiveness in the project charter for Phase I. The measures and summary results for each are shown here. A more in depth look at the results for each measure, including a description of the work done and overall impact to the process, is provided in the Phase I: Detailed Results section of this document.

1. Reduce number of data sources used to capture, analyze and generate final documents from six to one (where "data source" is any document or system used)

$\checkmark$ TARGET ACHIEVED: Reduced number of data sources from 6 to 1

2. Minimize number of data values documented by NIST Technical Contact (where "documented" means written or typed into any data source)

$\checkmark$ TARGET ACHIEVED: Reduced average number of data values documented by $85.8 \%$, from an average of 734 inputs to an average of 104 inputs

- Number of manual inputs reduced by $90.3 \%$, from an average of 730 to an average of 71

- Improved percentage of selectable input values from just $0.5 \%$ to $31.7 \%$ of total inputs

3. Reduce number of duplicate inputs required by NIST Technical Contact to produce final test folder documents to zero

$\checkmark$ TARGET ACHIEVED: Reduced number of duplicate inputs from 308 to *7

*Note: Initial efforts reduced the number of duplicate inputs to zero; upon review of the new program, seven key inputs were identified for double entry for data integrity purposes.

4. Reduce number of manual inputs required to obtain all necessary characteristics of the standard to just one (Name of Standard)

$\checkmark$ TARGET ACHIEVED: Reduced number of manual inputs required from 21 to 1

- $95 \%$ reduction in manual input values

5. Reduce manual time required for Data Analysis \& Report Generation (including Test Folder cover letter) to less than one hour

$\checkmark$ TARGET ACHIEVED: Reduced manual time for Data Analysis \& Report

Generation from 1 day to less than 1 hour 


\section{Phase I: Detailed Results}

\section{Phase I Deliverables}

The team identified six deliverables for phase I of this project. Five of the six deliverables have been achieved; the sixth deliverable was moved to phase II by agreement of the entire project team. The deliverables and a brief description of the work completed is provided here.

1. LabVIEW Program capable of:

a. Capturing all required inputs in LabVIEW and eliminating duplicate data entry from receipt of equipment through completion of the test folder (excludes Review \& Approval)

b. Calculating measurement points, data analysis and final results for review and approval

c. Creating required output documents with accepted results DELIVERABLE ACHIEVED

Based on process documentation, the team identified what information is required to complete a calibration, when the information is known (what step in the process) and the source of that information. The team worked together to create a wire frame for how the user interface should be presented for each of the major process steps. Finally, LabVIEW code was developed for each of the major process steps, then linked together to create the Phase I program. Throughout code development, the team met to review status, provide feedback, address issues and identify next steps. The result is a single LabVIEW program capable of capturing all required inputs for a calibration to be completed, analyzing results of the calibration and generating final calibration report documents while minimizing the number of inputs requiring manual input by the NIST Technical Contact.

2. Applicable Working Standards information converted to electronic form that is accessible by LabVIEW DELIVERABLE ACHIEVED

Working Standards (e.g. PG32) refer to characteristics for all standard piston gauges, the associated standard mass sets, bases and fluids used for the piston gauge calibration services. Dependencies exist between the piston gauges, mass sets, bases and fluids used. For example, PG32 only works with certain bases and mass sets. These dependencies, previously undocumented in a single, organized format, must be known in order to set up and execute a calibration. The team worked to document these dependencies so they could be incorporated into a Working Standards database accessible by the Phase I LabVIEW program. Creation of the database has significantly decreased the number of input values requiring manual entry by the NIST Technical Contact.

3. Approval for implementation of application(s) to be used for review and approval of official test folder documents (Calibration Report(s), Test Folder Cover Letter, \#3 Copy of NIST-64) DELIVERABLE ACHIEVED

One of the core efforts of the Colleagues' Choice Innovations in Measurement Science (C2IMS) project to Transform NIST Calibration Services is focused on developing a Calibration Customer Portal to "improve the quality of service we provide our customers and increase the dissemination of the SI (International System of units)." The portal will be a dedicated module within the NIST-wide Customer Relationship Management (CRM) application. The Piston Gauge Calibration team will work with the C2IMS project team to identify requirements for the portal including, but not limited to, workflow for electronic review and approval of reports, digital signature for electronic signing of completed reports 
and the ability to provide secure, electronic delivery of final reports to the Customer. Many of these capabilities will be developed and piloted as part of Phase II of this project.

4. Identification and development of physical set-up requirements to replace trim masses with pressure transducers / absolute gauges for all pneumatic pressure ranges in scope DELIVERABLE ACHIEVED

The current measurement process requires loading and unloading of nominal masses on each piston followed by the addition of trim masses on one side until a balanced condition is achieved. In the current method, trim masses are manually added and/or removed by the NIST Technical Contact, often with tweezers. In order to make an attempt at full automation of the calibration process, it was necessary for the team to eliminate the need for trim masses.

Building upon previous research [2], the team designed a new method using transducers to measure the pressure difference between the piston assemblies instead of using trim masses to achieve a balanced condition, with minimal effect on the final uncertainty of the calibration. In order to cover the full pneumatic pressure range, two transducers controlled by a custom built manifold are required. The manifold assembly includes LabVIEW coding for automated process control and capture of transducer data. The Phase I LabVIEW program has been designed to support both the current trim mass method and the new transducer method. The result of Phase I is approval to implement the Phase I LabVIEW program using both methods for comparison purposes. The current trim mass method will continue to be the accepted method for calibrations until results of the new transducer method have been verified and accepted across the full pneumatic pressure range. Formal acceptance of the transducer method is a Phase II deliverable.

5. Historical calibration records converted to electronic format and accessible by LabVIEW DELIVERABLE MOVED TO PHASE II (7/15/2015)

During development of the Phase I LabVIEW program, the team determined electronic access to historical calibration records was not crucial to Phase I success and could be delayed until Phase II of the project. Details of previous set up configurations do not need to be available electronically due to the efficiency of the new LabVIEW program and the updated final report template now contains a brief statement requiring only the NIST ID Number and Completion Date of the last calibration of the instrument done by NIST. Based on this information, the team decided to focus available resources on the development of the new transducer method.

6. A go/no-go decision for development and implementation of an automated mass handling device DELIVERABLE ACHIEVED

Development of the new transducer method to replace the current trim mass method has allowed the team to move forward with plans to introduce automated mass handling capabilities for the nominal masses. This led to a Go [Go is better, so it doesn't look like an acronym, or "go"] decision to purchase a commercial off the shelf Automated Mass Handler $(\mathrm{AMH})$ and the identification of a potential second AMH currently supporting an IMS project.

Phase II efforts will focus on:

- developing automated process control, excluding automated mass handling capabilities, and

- determining how to introduce automated mass handling capabilities into the calibration process. 
Implementation of automated mass handling capabilities will be the focus of Phase III. 


\section{Calculating Results for Phase I Measures}

Results were calculated based on the following assumptions:

1. Results are for the calibration of one single Deadweight Piston Gauge, service ID 29010C

2. NIST-owned base and NIST-owned masses are used

3. Number of masses determined by averaging actual number of input values from 3 test folders:

- Average number of masses per measurement loaded on the standard (STD) piston gauge is 6

- Average number of masses per measurement loaded on the Test piston gauge is 9

- Average number of trim masses per measurement is 4

4. Phase I program replaces use of trim masses with the new transducer method

5. A duplicate input is an input value entered into any data source more than one time

\section{MeAsure 1}

Reduce number of data sources used to capture, analyze and generate final documents from six to one (where "data source" is any document or system used)

\section{$\checkmark$ TARGET ACHIEVED: Reduced number of data sources from 6 to 1 (see Table)}

DESCRIPTION: The previous method required the user to enter and re-enter data into multiple data sources over the course of the calibration process. The Phase I improvements have established a LabVIEW program capable of capturing the required inputs directly into the program at the time they are known and recalling the data when needed for data analysis and report generation later in the calibration process.

IMPACT: These improvements significantly reduce the amount of time and opportunities for error in the calibration process. In addition, the entire Phase I LabVIEW program can be run on the lab computer. This eliminates the need to use the legacy computer currently running the Fortran program as well as the steps to transfer the outputs of the Fortran program to a separate computer via floppy disk. Implementation of the Phase I LabVIEW program mitigates the risk of legacy equipment failure and improves knowledge transfer capabilities from one NIST Technical Contact to the next.

\begin{tabular}{|c|c|c|c|c|c|}
\hline \multirow{2}{*}{$\begin{array}{l}\text { Process } \\
\text { Step }\end{array}$} & \multirow{2}{*}{ Activity } & \multicolumn{2}{|r|}{ Original } & \multicolumn{2}{|c|}{ Phase I End } \\
\hline & & Data Source & Method & Data Source & Method \\
\hline $\begin{array}{l}\text { Equipment } \\
\text { Receipt }\end{array}$ & $\begin{array}{l}\text { Capture Equipment } \\
\text { Receipt information }\end{array}$ & $\begin{array}{l}\text { Pressure Log } \\
\quad \text { Book }\end{array}$ & $\begin{array}{c}\text { Manual entry } \\
\text { (handwritten) into hard } \\
\text { copy log book }\end{array}$ & LabVIEW & $\begin{array}{c}\text { Manual entry (typed) into } \\
\text { LabVIEW program }\end{array}$ \\
\hline $\begin{array}{l}\text { Setup } \\
\text { Activity }\end{array}$ & $\begin{array}{l}\text { Determine } \\
\text { measurement points, } \\
\text { perform setup } \\
\text { activities }\end{array}$ & $\begin{array}{l}\text { Measurement } \\
\text { Point } \\
\text { Calculation }\end{array}$ & $\begin{array}{c}\text { Manual entry (typed) into } \\
\text { Excel template }\end{array}$ & LabVIEW & $\begin{array}{l}\text { Automated calculation of } \\
\text { measurement points; } \\
\text { Manual entry of setup } \\
\text { activity measurements } \\
\text { into LabVIEW program }\end{array}$ \\
\hline Calibration & $\begin{array}{l}\text { Capture calibration } \\
\text { measurement values }\end{array}$ & $\begin{array}{c}\text { Crossfloat Data } \\
\text { Table }\end{array}$ & $\begin{array}{l}\text { Manually written on hard } \\
\text { copy printout }\end{array}$ & LabVIEW & $\begin{array}{l}\text { Manual entry directly } \\
\text { into LabVIEW program }\end{array}$ \\
\hline \multirow{2}{*}{$\begin{array}{c}\text { Data } \\
\text { Analysis }\end{array}$} & $\begin{array}{c}\text { Perform Part I of Data } \\
\text { Analysis } \\
\text { (Fortran Program) }\end{array}$ & $\begin{array}{c}\text { Fortran } \\
\text { Program (.DAT } \\
\text { file) }\end{array}$ & $\begin{array}{l}\text { Manual entry (typed) into } \\
\text { Fortran program }\end{array}$ & \multirow{2}{*}{$\begin{array}{l}\text { LabVIEW } \\
\text { (Parts I \& II } \\
\text { combined) }\end{array}$} & \multirow{2}{*}{$\begin{array}{l}\text { Automated analysis and } \\
\text { presentation of results by } \\
\text { LabVIEW program }\end{array}$} \\
\hline & $\begin{array}{l}\text { Perform Part II of Data } \\
\text { Analysis } \\
\text { (Uncertainty Analysis) }\end{array}$ & $\begin{array}{l}\text { MicroSoft Excel } \\
\text { Uncertainty } \\
\text { Analysis Macro }\end{array}$ & $\begin{array}{l}\text { Manual entry (typed) } \\
\text { plus upload of Fortran } \\
\text { pr4 file into Excel macro }\end{array}$ & & \\
\hline $\begin{array}{c}\text { Report } \\
\text { Generation }\end{array}$ & $\begin{array}{l}\text { Create final } \\
\text { documents } \\
\text { (Calibration Report \& } \\
\text { Cover Letter) }\end{array}$ & $\begin{array}{l}\text { MicroSoft Word } \\
\text { Templates }\end{array}$ & $\begin{array}{l}\text { Manual entry (typed) into } \\
\text { Word template }\end{array}$ & LabVIEW & $\begin{array}{l}\text { Automated generation of } \\
\text { final documents by } \\
\text { LabVIEW program }\end{array}$ \\
\hline
\end{tabular}




\begin{tabular}{|l|l|l|r|}
\hline & TOTAL & 6 Sources & 1 Source (LabVIEW) \\
\hline
\end{tabular}

\section{MeASURE 2}

Minimize average number of data values documented by NIST Technical Contact (where "documented" means written or typed into any data source)

$\checkmark$ TARGET ACHIEVED: Reduced average number of data values documented by $85.8 \%$, from an average of 734 inputs to an average of 104 inputs (see Table 2)

- Number of manual inputs reduced by $90.3 \%$, from an average of 730 to an average of 71

- Improved percentage of selectable input values from just $0.5 \%$ to $31.7 \%$ of total inputs

DESCRIPTION: Documented inputs are defined as an input value written on or typed into a data source by the NIST Technical Contact. By developing a LabVIEW program capable of capturing the required inputs directly into the program at the time they are known and recalling the data when it is needed again later in the process, we have significantly reduced the number of data values the NIST Technical Contact must document. In addition, many of the input values required have a known set of potential values. Defining the potential values for these inputs allowed us to create "selectable" inputs - inputs that can be selected instead of entered in an open text format. Phase II will further improve these results through automated capture of measurement values.

IMPACT: The $85.8 \%$ reduction in the total number of data values documented by the NIST Technical Contact has significantly reduced the opportunities for error in the calibration process. In addition, the amount of time required to determine preliminary measurement points, complete data analysis and generate final documentation has dramatically decreased (see measure 5 results for more details). The impact of these improvements is furthered by improving the data integrity of the data values that are documented by the NIST Technical Contact.

TABle 2: DATA VALUE InPUT METHODS

\begin{tabular}{|c|c|c|c|c|c|c|c|}
\hline \multirow{2}{*}{$\begin{array}{l}\text { Process } \\
\text { Step }\end{array}$} & \multirow[b]{2}{*}{ Activity } & \multicolumn{3}{|c|}{ Original } & \multicolumn{3}{|c|}{ Phase I End } \\
\hline & & $\begin{array}{l}\text { Manual } \\
\text { Inputs }\end{array}$ & $\begin{array}{l}\text { Selectable } \\
\text { Inputs }\end{array}$ & $\begin{array}{l}\text { TOTAL } \\
\text { Inputs }\end{array}$ & $\begin{array}{l}\text { Manual } \\
\text { Inputs }\end{array}$ & $\begin{array}{l}\text { Selectable } \\
\text { Inputs }\end{array}$ & $\begin{array}{l}\text { TOTAL } \\
\text { Inputs }\end{array}$ \\
\hline $\begin{array}{l}\text { Equipment } \\
\text { Receipt }\end{array}$ & $\begin{array}{l}\text { Capture Equipment } \\
\text { Receipt information }\end{array}$ & 11 & 0 & 11 & 19 & 11 & 30 \\
\hline $\begin{array}{l}\text { Setup } \\
\text { Activity }\end{array}$ & $\begin{array}{c}\text { Determine } \\
\text { measurement points, } \\
\text { perform setup activities }\end{array}$ & 46 & 0 & 46 & 2 & 7 & 9 \\
\hline Calibration & $\begin{array}{l}\text { Capture calibration } \\
\text { measurement values }\end{array}$ & 236 & 0 & 236 & 50 & 10 & 60 \\
\hline \multirow{2}{*}{$\begin{array}{c}\text { Data } \\
\text { Analysis }\end{array}$} & $\begin{array}{c}\text { Perform Part I of Data } \\
\text { Analysis } \\
\text { (Fortran Program) }\end{array}$ & 369 & 0 & 369 & \multirow[b]{2}{*}{0} & \multirow[b]{2}{*}{3} & \multirow[b]{2}{*}{3} \\
\hline & $\begin{array}{c}\text { Perform Part II of Data } \\
\text { Analysis } \\
\text { (Uncertainty Analysis) }\end{array}$ & 3 & 4 & 7 & & & \\
\hline $\begin{array}{c}\text { Report } \\
\text { Generation }\end{array}$ & $\begin{array}{c}\text { Create final documents } \\
\text { (Calibration Report \& } \\
\text { Cover Letter) }\end{array}$ & 65 & 0 & 65 & 0 & 2 & 0 \\
\hline \multirow{2}{*}{ TOTAL } & Number of Inputs & 730 & 4 & 734 & 71 & 33 & 104 \\
\hline & $\%$ of Total Inputs & $99.5 \%$ & $0.5 \%$ & $100 \%$ & $68.3 \%$ & $31.7 \%$ & $100 \%$ \\
\hline
\end{tabular}




\section{MeASURE 3}

Reduce number of duplicate inputs required by NIST Technical Contact to produce final test folder documents to zero

$\checkmark$ TARGET ACHIEVED: Reduced number of duplicate inputs from 308 to *7 (see Table 3)

*Note: Initial efforts reduced the number of duplicate inputs to zero; upon review of the new program, seven key inputs were identified for double entry for data integrity purposes.

DESCRIPTION: Duplicate inputs are defined as an input value entered into any data source more than once. Initial efforts were successful in eliminating all duplicate inputs. However, during our review of the new program, the team recognized seven key input values capturing the characteristics of the test instrument that are critical to the calibration process. These seven values are typed in manually during equipment receipt and cannot be validated for accuracy upon entry. Errors in these values are typically identified much later in the process. Depending on when the error(s) are identified, a significant amount of rework, including rererunning the entire calibration, may be required. In order to ensure data integrity at the point of entry, the decision was made to prompt the user to enter each of these values twice, compare the values and immediately alert the user to re-enter the values if there is a discrepancy.

The seven key inputs capturing characteristics of the test instrument are:

- Piston Assembly Mass

- Piston Assembly Density

- Thermal Expansion Coefficient of Piston

- Thermal Expansion Coefficient of Cylinder

- Nominal Effective Area

- Minimum Instrument Pressure

- Maximum Instrument Pressure

IMPACT: This result reduces the amount of time and opportunities for error in the calibration process and eliminates the opportunity for costly rework due to manual entry errors.

TABLE 3: DUPLiCATE INPUT VALUES

\begin{tabular}{|c|c|c|c|c|c|c|c|}
\hline \multirow{2}{*}{$\begin{array}{l}\text { Process } \\
\text { Step }\end{array}$} & \multirow[b]{2}{*}{ Activity } & \multicolumn{3}{|c|}{ Original } & \multicolumn{3}{|c|}{ Phase I End } \\
\hline & & $\begin{array}{l}\text { Original } \\
\text { Inputs }\end{array}$ & $\begin{array}{l}\text { Duplicate } \\
\text { Inputs }\end{array}$ & $\begin{array}{l}\text { TOTAL } \\
\text { Inputs }\end{array}$ & $\begin{array}{l}\text { Original } \\
\text { Inputs }\end{array}$ & $\begin{array}{c}\text { Duplicate } \\
\text { Inputs }\end{array}$ & $\begin{array}{l}\text { TOTAL } \\
\text { Inputs }\end{array}$ \\
\hline $\begin{array}{l}\text { Equipment } \\
\text { Receipt }\end{array}$ & $\begin{array}{l}\text { Capture Equipment } \\
\text { Receipt information }\end{array}$ & 11 & 0 & 11 & 23 & *7 & 30 \\
\hline $\begin{array}{l}\text { Setup } \\
\text { Activity }\end{array}$ & $\begin{array}{c}\text { Determine } \\
\text { measurement points, } \\
\text { perform setup activities }\end{array}$ & 39 & 7 & 46 & 9 & 0 & 9 \\
\hline Calibration & $\begin{array}{l}\text { Capture calibration } \\
\text { measurement values }\end{array}$ & 236 & 0 & 236 & 60 & 0 & 60 \\
\hline \multirow{2}{*}{$\begin{array}{c}\text { Data } \\
\text { Analysis }\end{array}$} & $\begin{array}{c}\text { Perform Part I of Data } \\
\text { Analysis } \\
\text { (Fortran Program) }\end{array}$ & 112 & 257 & 369 & \multirow{2}{*}{3} & \multirow[b]{2}{*}{0} & \multirow[b]{2}{*}{3} \\
\hline & $\begin{array}{c}\text { Perform Part II of Data } \\
\text { Analysis } \\
\text { (Uncertainty Analysis) }\end{array}$ & 2 & 5 & 7 & & & \\
\hline $\begin{array}{c}\text { Report } \\
\text { Generation }\end{array}$ & $\begin{array}{c}\text { Create final documents } \\
\text { (Calibration Report \& } \\
\text { Cover Letter) }\end{array}$ & 26 & 39 & 65 & 2 & 0 & 2 \\
\hline \multirow{2}{*}{ TOTAL } & Number of Inputs & 426 & 308 & 734 & 97 & $* 7$ & 104 \\
\hline & \% of Total Inputs & $58.0 \%$ & $42.0 \%$ & $100 \%$ & $93.3 \%$ & $6.7 \%$ & $100 \%$ \\
\hline
\end{tabular}

*Inputs identified as key values to the calibration; these inputs are entered twice during equipment receipt for data integrity purposes 


\section{MeASURE 4}

Reduce number of manual inputs required to obtain all necessary characteristics of the standard to just one (Name of Standard)

$\checkmark$ TARGET ACHIEVED: Reduced number of manual inputs required from 21 to 1

- $95 \%$ reduction in manual input values

DESCRIPTION: The original Fortran program required 21 input values to define the characteristics of the standard. These values were maintained as hard copy documents in a 3ring binder, which required the user to first locate the necessary page and then accurately enter the information into the Fortran program. During Phase I efforts, all applicable Working Standards information was incorporated into a database accessible by the Phase I LabVIEW program. Now, the user selects the Name of the Standard during Setup Activities and all other characteristics are known. That is a 95\% reduction in the number of input values required for all characteristics of the standard to be known during data analysis.

IMPACT: This result significantly reduces the amount of time and opportunities for error in the calibration process.

\section{MeAsure 5}

Reduce manual time required for Data Analysis \& Report Generation (including test folder cover letter) to less than one hour

$\checkmark$ TARGET ACHIEVED: Reduced manual time for Data Analysis \& Report Generation from $\sim 1$ day to less than 1 hour

DESCRIPTION: A detailed time study for the previous method was not completed, but through interviews and limited observation, we estimated Data Analysis and Report Generation for the previous method took about 6 to 8 hours to complete. The Phase I LabVIEW program now completes Data Analysis activities at the push of a button. Once reviewed, a second push of the button generates the final reports.

IMPACT: This result significantly reduces the amount of time, level of effort and opportunities for error in the Data Analysis and Report Generation steps of the calibration process. 


\section{A LOOK AHEAD: Phase II OVERVIEW}

Phase II will focus on introducing automated capture of measurement values and automated process control of the measurement process with the exception of loading and unloading masses (this will be addressed in Phase III).

\section{PhaSe II OBJECTIVES}

Further reduce opportunities for error, time required and level of experience required in the piston gauge calibration service by:

- Formally implementing the transducer method in the NIST calibration quality system manual for the service (QM-III) for the full pneumatic pressure range,

- Automating capture of the majority (>50\%) of measurement data,

- Implementing $100 \%$ electronic test folders from creation to closure of the test folder (this excludes administrative activities completed by the Calibration Administrator prior to creation and after closure of the test folder),

- Creating an electronically accessible version of historical records to further reduce data entry requirements,

- Implementing technical solutions to automate process control capabilities during the calibration process (with the exception of loading and unloading masses), and

- Clearly defining how automated mass handling capabilities will support long term capabilities of the piston gauge calibration service and developing a plan for implementation.

\section{Phase II Deliverables}

The team has identified the following deliverables for Phase II:

1. Updated QM-III to use the transducer method for piston gauge calibration services

2. Calibration Support System (CSS) $\rightarrow$ LabVIEW Interface to push appropriate test folder data to LabVIEW triggered by creation of a test folder in CSS

3. Automated capture of more than $50 \%$ of observation data

4. Automated process control during calibration (exception is loading/unloading of masses)

5. Historical calibration records converted to electronic format and accessible by LabVIEW

6. Electronic workflow, including digital signature capability, for review and approval of final calibration documents

7. Interface back to CSS (source still TBD) to provide Test Folder completion dates (3) and electronic copy of official documents when test folder is updated to "ready for shipment"

8. Secure, electronic delivery of final calibration documents to the Customer

Measures of effectiveness for Phase II are currently being developed by the team.

Team Members - Updates for Phase II

Jay Hendricks, Project Sponsor:

- Responsible for funding, physical space, sign off

Kevin Douglass, Technical Project Lead:

- Responsible for defining acceptance criteria, validation of product

Greg Driver, Dawn Cross, Process Owner / NIST Technical Contact:

- Responsible for defining requirements, facilitating knowledge transfer, user acceptance testing, validation of user documentation, calibration service support upon implementation of Phase II changes

John Quintavalle, LabVIEW Developer:

- Responsible for development, system testing and implementation support

Katie Schlatter, Project Manager / Process Engineer:

- Responsible for scheduling, project management, process improvement assessment and design 


\section{REFERENCES}

[1] NIST, "NIST Calibration Services for Pressure Using Piston Gauge Standards," NIST Special Publication 250-39, 2009

[2] Scherschligt et. al., "Pressure Balance Cross-Calibration Method Using a Pressure Transducer as Transfer Standard," NCSLI Measure, vol 11, pp 28-33, 2016 